\title{
NATURE SASKATCHEWAN NEWS
}

Nature Saskatchewan and Saskatoon Nature Society hosted the Fall Meet held in Saskatoon from September 29 to October 1, 2006. The Awards Banquet took place on Saturday, September 30. The annual awards program recognizes the contributions of volunteers to Nature Saskatchewan and to conservation. The awards, and their recipients, are listed below in alphabetical order.

\section{Cliff Shaw Award}

Named for the second editor of Blue Jay, naturalist and writer Cliff Shaw, this award is presented annually to recognize an outstanding contribution in the past four issues of the magazine. Special consideration is given to articles by new contributors. This year's recipients are Danna Schock and Trent Bollinger for their article in the September 2005 issue, 'An apparent decline of Northern Leopard Frogs (Rana pipiens) on the Rafferty Dam Mitigation Lands near Estevan, SK.'

\section{Conservation Award}

The Conservation Award is presented each year to an individual whose total contribution to conservation is outstanding. The award may be presented for a specific project or for conservation work over a period of years. The recipient of this years award is Alan Appleby who served for over 16 years as the Director of Lands, Director of Parks and Assistant Deputy Minister of Resource Programs in what is now called Saskatchewan Environment. A highlight in Alan's career in government was the passage of the Parks Act in 1986, which led to the creation of 14 new parks, including Saskatchewan's first wilderness park, Clearwater River Provincial Park. He was also involved in negotiating the Grasslands National Park agreement which led to the founding of the current park. Alan was Conservation Director with the Canadian Parks and Wilderness Society (CPAWS), Saskatchewan Chapter, from 2000 to 2006.

\section{Fellows Award}

Since 1987, the Society has designated members who have made a long and outstanding contribution as "Fellows of the Saskatchewan, Natural History Society". In 2006, five members were recognized with this award: Attila Chanady, Dale Hjertaas, Anna Leighton, Ted Leighton and Dianne Secoy Smith.

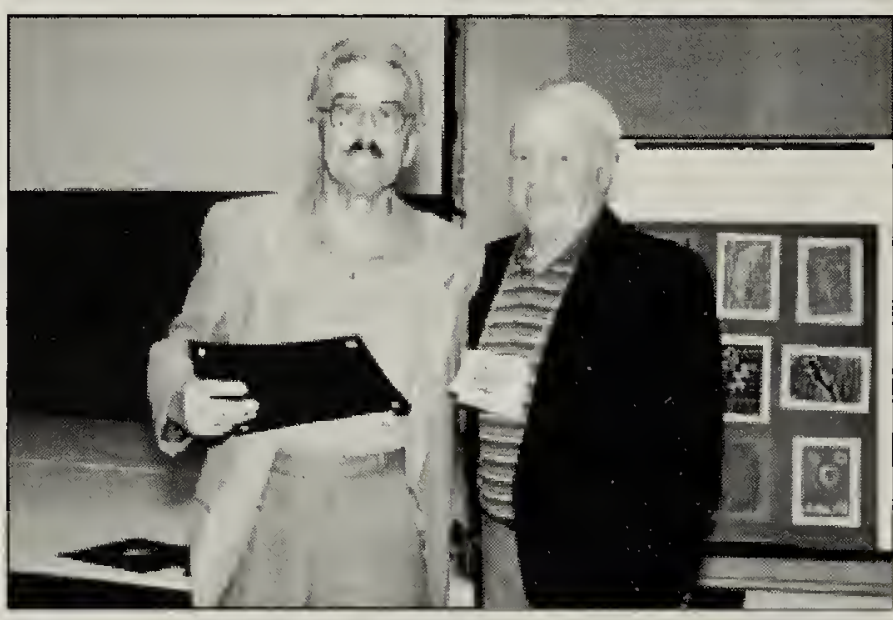

Attila Chanady receives Fellows Award from Nature Saskatchewan President Bill McKenzie.

Branimir Gjetvaj

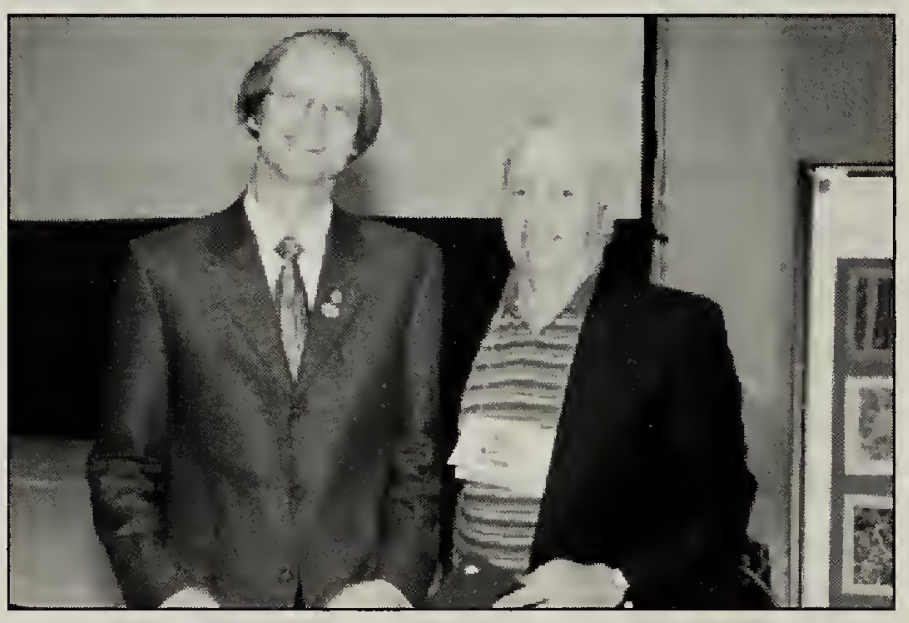

Dale Hjertaas receives Fellows Award from Bill McKenzie. Branimir Gjetvaj 


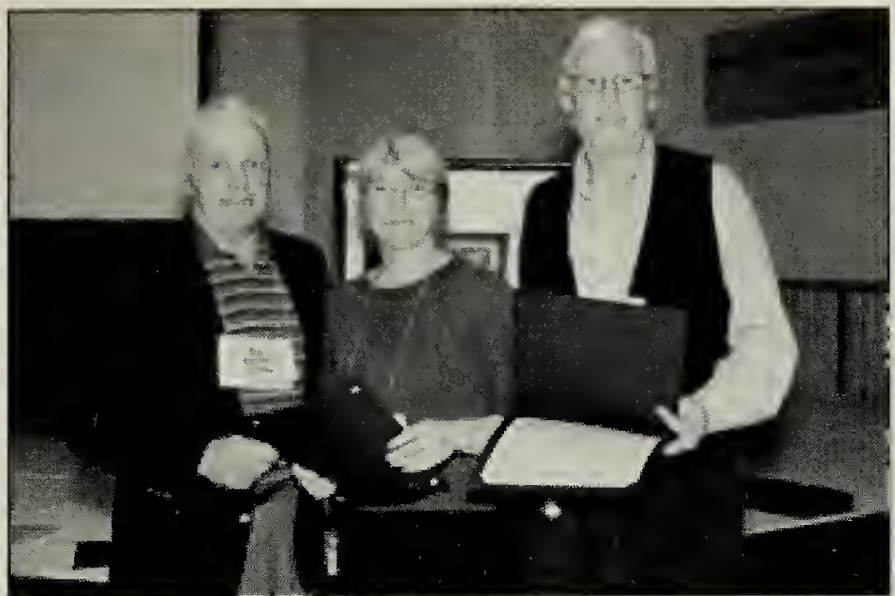

Anna and Ted Leighton receive Fellows Award from Bill McKenzie

Branimir Gjetvaj

\section{Larry Morgotch Memorial Award}

Initiated by the Yorkton Natural History Society in memory of former member Larry Morgotch, this award is presented to the member showing the best photographs at the Meet's Friday night presentation. The winner this year was Anna Leighton for her presentation on the Great Sand Hills.

\section{Long-term Service Award}

This award is presented to an individual who has made an ongoing contribution to the society through their volunteerism and their energy. This year's recipients were the two people who organize the Christmas Bird and Mammal counts, and compile and computerize the data: Robert Johanson and Alan Smith.

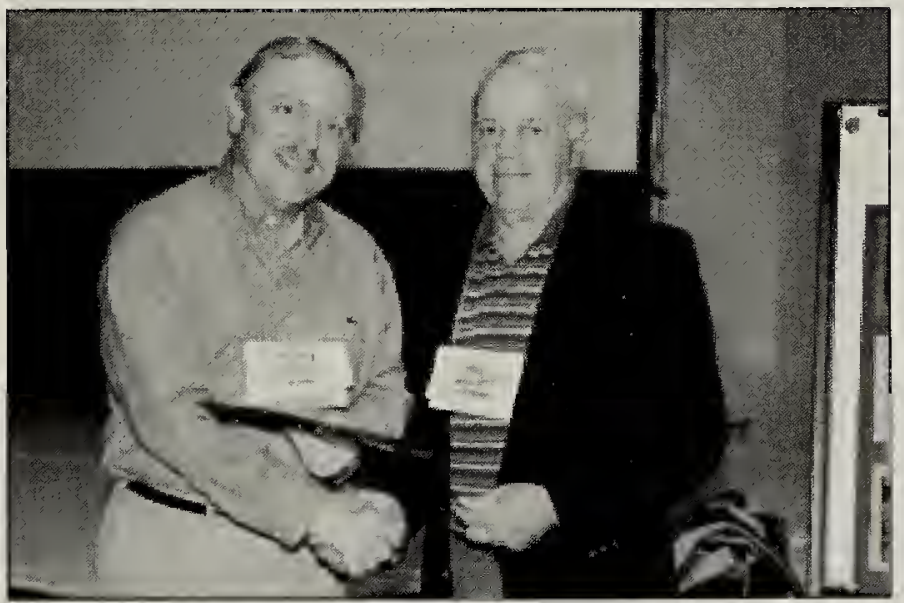

Robert Johanson receives Long-term Service Award from Bill McKenzie Branimir Gjetvaj
Natural History Scholarship

Nature Saskatchewan encourages academic achievement and excellence with a scholarship for graduate students of excellent academic standing whose studies are in keeping with the goals and objectives of the Society. The 2006 recipients are Mark Bidwell and Arun Govind. Mark is a Ph.D. student at the University of Saskatchewan, studying the influence of fire and logging on the distribution, abundance and breeding success in boreal birds. Arun Govind is a Ph.D. student in the Geography Department at the University of Saskatchewan, studying shrub habitat dynamics in a mixed grass prairie. His fieldwork is being conducted in the Grasslands National Park in southern Saskatchewan.

\section{Volunteer of the Year Award}

This award acknowledges individuals who have devoted significant time and energy to promoting the goals of the Society. This year the Society acknowledges two dedicated volunteers Attila Chanady, the out-going president of Nature Saskatchewan and Mary Aird, the Administrative Director on the Nature Saskatchewan Board. Attila has made a number of major contributions to the Society, both as President for the past two years and previously in a number of capacities on the Board of Directors including Vice-President and Conservation Director. Mary Aird joined the Board during the fall of 2003. In June of 2004, she became involved in a review and revisions of the Board's Policy Manual. All of the directors were involved in reviewing policies related to their areas of responsibility; Mary compiled, formated, and finalized the manual. 